Separation and Striation of Rarefied Gases under the Influence of the Electric Discharge

This content has been downloaded from IOPscience. Please scroll down to see the full text. 1892 Proc. Phys. Soc. London 12147

(http://iopscience.iop.org/1478-7814/12/1/309)

View the table of contents for this issue, or go to the journal homepage for more

Download details:

IP Address: 141.161.91.14

This content was downloaded on 05/09/2015 at 10:29

Please note that terms and conditions apply. 
It is obvious, however, that by taking a smaller range of pressure-say from the lowest to 2000 millim., or from 4000 millim. to the highest pressure, and by altering the constants, a very much better agreement would be obtained. Extrapolation beyond the limits of pressure chosen would, however, introduce very large errors indeed.

In conclusion it may, I think, be stated that in a great number of cases, including pairs of widely different bodies, the formula of Ramsay and Young gives better results than that of M. Colot; the latter, which is very convenient, may, however, be employed, even for very wide ranges of pressure, when the constant $B$ is small, and for small ranges of pressure when $B$ is large.

\section{Separation and Striation of Rarefied Gases under the}

Influence of the Electric Discharge. By E. C. C. BAL ${ }^{*}$.

Sout time ago, on examining with a spectroscope a vacuumtube which happened to contain a small quantity of hydrogen, during the passage of the electric spark I noticed that the hydrogen lines, while strongly visible in the negative glow, could not be seen in the body of the tube. The hydrogen appeared to be, in fact, withdrawn from the tube and collected about the negative pole. Finding the same result in a tube which I fitted up for the purpose, it appeared to me to point to a separation of the gawes in the tube; and I determined to make a series of experiments with a view to investigating the matter and the behaviour generally of different gases under similar conditions.

The tubes I employed wer $\theta$ about 9 inches long and $\frac{3}{4}$ inch internal bore. The electrodes were of aluminium wire, and, except in certain cases to which I shall refer, about $1 \frac{1}{2}$ inch in length. Two of these tubes were connected to the pump at the same time, one direct and the other through tubes for the absorption of mercury vapour ; so that in all the experiments results were obtained in the presence and in the absence of mercury rapour. Gas-generators, fitted with

rul. Xill.

* Read February 10, 1893. 
purifying and drying apparatus, were connected so as to allow of varying quantities of the particular gases noler examination being admitted to the tubes as might be required. The pump, I may mention, was a modified form of the Geissler mercury-pump, to which I was able to attach an automatic apparatus for working it-a very great saving of labour. Measurements of the vacua were obtained by means of an ordinary barometer-gauge, and varied from 15 millim. to $\frac{3}{4}$ millim.

I first worked with varying quantities of carbon dioxide and hydrogen. On using certain mixtures of these gases exhausted to about $\frac{3}{4}$ millim., when the current was first passed a white glow appeared throughont the trube, no striæe being visible, giving a mixed spectrum of the two gases. After a few seconds the negative glow changed to a pink colour, and well-defined striæ, whiter than the preceding glow, began to appear. On watching this change with the spectroscope, the bydrogen lines in the trube were seen to become fainter and gradually to disappear, leaving only the spectrum of arbon clioxide, while those in the negative glow became extremely brilliant. The current was then stopped, and the tube allowed to rest for about an hour, when, the current being passed again, the same phenomenon precisely occurred. Judging that if this were caused by actual separation of the two gases, it ought to be possible to fractionate out the hydrogen into anvther tube, I endeavoured for a long time unsuccessfully to do so; but at length succeeded by using a double tube of the shape shown in the figure. The longer of the tubes: consisted of two chambers joined by capillary tubing, the smaller tube being comnected to one of these by a narrow neck capable of being sealed off. Both tubes were

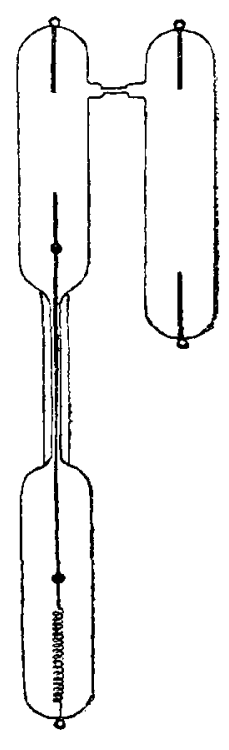
furnished with electrodes. One of those in the large tube was sufficiently long to project through the capillary into the second chamber, and being connected at its base to the sealed platinum by a weak piral wire 
could be dropped sufficiently far to touch the opposite electrode. This rod was made of copper, as being heavier than aluminium. It fitted the capillary fairly well, and was furnished with small stops of cotton-wool in order to close the capillary, and thus prevent as much as possible the diffusion of the gases. The tube, after being filled with the gases carbon dioxide and hydrogen, was exhausted and sealed from the pump. The copper rod was caused to touch the opposite electrode, and the current was passed so as to make the whole of the long tube the negative pole and the electrode at the lower end of the smaller tube the positive. The current was continued for a considerable time, when the connecting-neck between the tubes was sealed off and the copper rod shaken back to the stop. On comparing the spectra of the two tubes, it was found that the small tube (containing the positive pole) showed only a trace of hydrogen, while the other showed it brilliantly.

'This, I think, may be considered a proof of an actual though not complete separation of the two gases.

I then tried hydrogen mixed with many other gasesamongst them nitrogen, carbon monoxide, sulphur dioxide, iodine, and mercury rapour; and in erery case, without exception, I found that the hydrogen was collected about the negative pole in ex:ctly the same manner as I have particularized.

I proceeded to examine mixtures of other gases. With carbon monoxide and carbon dioxide, the carbon monoxide is separated out and appears in the negative glow. With carbon dioxide and nitrogen the carbon dioxide is separated out, while the nitrogen remains in the tube, the separation being remarkably distinct. In this case it is the heavier gas which is separated out; and the same is found with carbon dioxide and sulphur dioxide, the sulphur dioxide appearing in the negative glow.

It would thus appear that the separation of two galses does not depend on their relative molecular weights. On examining a tube of air, however, the components of which are of fairly equal molecular weight, a separation was found to be very difficult, and only occurred after carrying the exhanstion to a much higher point than was usually necessary. The 
nitrogen remained in the tube, and the negative glow gave a spectrum presumahly oxygen; I say presumably, for I am unable to see what else it can be. I was unable to produce the same spectrum in a tube with oxygen, but I was prevented from proceeding further. The spectra of oxygen Professor Schuister has shown to be very varied under different conditions. Is it not possible that the two spectra in an oxygen tube, the banded one in the negative glow, and the brightline one in the rest of the tube, may be due to separation of two gases?

From these experiments it is evident that when the electric current is passed through a rarefied mixtmre of two gases, a process similar to electrolysis is set up, one of the gases being separated out and collected about the negative pole, the other gas remaining in the tube; the proof being that the gas separated out may be fractionated into another tube by the method I have above described. In pursuing these experiments I was struck by the apparent close connexion between separation and striation; that is to say, I found strongly marked striæ when there was good separation, and feeble striæ when the separation was difficult; I also found that the first appearances of these phenomena were coincident, the formation of striæ being always the sign of the commencement of separation. There were no exceptions to this, the action in all the tubes I made being the same.

It was evident to me that, if the connexion were real and the separation of the gases could in some way be prevented, by avoiding the negative glow, stria would not be formed. I accordingly made a tube the negative pole of which did not protrude from the little glass collar in which it was placed, the positive electrode being made as usual. The tube was filled with a mixture of hydrogen and carbon dioxide and exhausted. At a pressure of 24 millim. the current was passed ; instead of a negative glow appeared a little bunch of light about $\frac{1}{8}$ inch below the negative point. If this bunch of light impinged on the side of the tube, the glass became strongly phosphorescent. At 4 millim. there was no bunch of light or negative glow; there was no sign of any strix, the tube giving a spectrum of bydrogen and carbon dioxide, and no evidence of separation. I then reversed the current ; imme- 
diately striæ formel, separation began and beame wellmarked.

I tried various mixtures of gases and always obtained the same result, viz., that when the negative glow was aroided by the use of the minute electrode point, neither strixe nor separation occurred, but in reversal of the current strongly marked striæ and good separation.

My next step was to experiment with a pure vapour, which, if my contention be correct, should not striate. It is known that a tube of pure mercury vapour does not stratify. I prepared a tube for the purpose, one end of which was connected with the pump and the other with a bulb containing mercury. After exhaustion, I strongly heated the tube and boiled the mercury, which thus distilled through the tube. On passing the current, as I expected, no striæ appeared, but simply a beautiful phosphorescence throughout the tube, giving a spectrum of pure mercury only. On ceasing to boil the mercury and ailowing the tube to cool, a small quantity of other gas was necessarily drawn in from the pump. Immediately striæe began to appear, beginning at the end of the tube connected with the pump; the negative glow changed at the same time and gave a spectrum containing other lines in addition to those of mercury, thus strongly confirming my previous conclusion.

Thinking that possibly the absence of strire might arise, not from the purity of the mercury vapour, but from its molecules being monatomic, I repeated the experiment with pure vapours of iodine, sulphur, arsenic, and mercuric iodide, which are not monatomic. The result was in each case precisely the same-the tube while heated showing no strix, but on cooling both striæe and separation.

Wishing if possible to obtain a pure gas which did not stratify at ordinary temperatures, I made many attempts to prepare a tube of pure hydrogen. The nearest approach to success was with hydrogen prepared from pure caustic potash and aluminium. The gas was then absorbed by red-hot palladium, which was re-heated in the vacuum. On passing the current, the tube showed an even phosphorescent light throughout, with a very faint line of the most delicate strixe, very difficult to distinguish. 'The stria did not become any 
plainer on carrying the exhaustion to a considerably higher point. I think it may be safely assumed that a tube of perfectly pure hydrogen would not striate at all.

From the foregoing results I think the following conclusions may be drawn :-

First, that when an electric current is passed through a rarefied mixture of two gases, one is separated from the other and appears in the negative glow.

Second, that striæ are caused by the separation of the two gases, and do not occur in a single pure gas or vapour.

\section{Discussion.}

Mr. Crookes said :-

In my Inaugural Address delirered before the Institution of Electrical Engineers on January 15th, 1891, I showed some experiments and gave reasons which had led me to believe that the stratifications seen when a high-tension current is passed through a rarefied gas were due to the gas not being homogeneous. I took the case of hydrogen in a vacuum-tube at a pressure of 2 millim. The gas was prepared from zinc and sulphuric acid, and was purified and dried in the usual manner, but with no special precautions against impurities. The exhaustion was effected with a mercury pump, thus leaving mercury vapour in the residual hydrogen.

The stratifications are tri-coloured-blue, pink, and grey. Nest the negative pole is a luminous layer; then comes a dark interval, or Faraday's dark space; and after this are the stratifications, the front component of each group blue, the next pink, and the third grey. The blue discs are somewhat erratic. At a certain stage of exhaustion all the blae cumponents of the stratification suldenly migrate to the front, forming one bright blue disc, and leaving the pink and grey components by themselves. When the tube contains a compound gaseous residue of this kind, the form of stratifications can be very considerably altered by varying the potential of the discharge. .... That the alteration depends simply on the difference of potential, the following experiment pretty clearly shows:Take a tube giving on the coil the coloured stratifications usually attributed to the presence of residual hydrogen, but which I find is due to a mixture of hydrogen, mercury, and 
hydrocarlon vapours. Then, by altering the break so as to produce frequent discharges of lower potential, the stratifications gradually change in slape and hecome all pink; again, altering the break, so als to send less rupid discharges at a much higher potential, once more we get the coloured stratifications. When in this state, if we introduce a water resistance into the circuit, so as to damp down the potential, exactly the same thing happens. The blue disk is caused by mercury; its spectrum is that of mercury only, without even a trace of the bright red line of hydrogen. Experiments not yet finished make it very probable that the pink dises are due to hydrogen, and that the grey dises indicate carbon. The tube contains nothing but lydrogen, mercury, and a minute trace of carbon; but witl all the resources at my command I have not been able to get hydrogen quite free from impurity. Indeed I do not think absolutely pure hydrogen has ever yet been obtained in a racuum-tule. I bave so far succeeded as to completely eliminate the mercury, and almost completely to remove the trace of carbon.

IX. Notes on some Recent Determinations of Moleculur Refraction and Dispersion. By. J. H. (Xtanstose, D.Se, F.R.S.:

Anoxa the various indices of refraction which have been published by different observers of late years, there are some which have led me to further studies bearing on the general relation of this branch of Physics to Chemical theory. The following notes relate to the new metallic carhonyls, the metals indium and gallium, sulphur, and to liquefied oxygen, nitrous oxide, and ethylene.

\section{Metallic Carbonyls.}

Messrs. Ludwig Mond and Nasini $\dagger$ determined the molecular refraction of nickel tetracarbonyl for the red ray of

* Read February 10, 1893.

$\dagger$ Lincei, Rendionnti, vii. 411. 